\section{Newton Kara-Junior}

Tais Renata Ribeira Parede

Marcony Rodrigues Santhiago

Rodrigo França Espindola

Maysa Godoy Gomes Mazurek

Regina de Souza Carvalho
Departamento de Oftalmologia. Faculdade de Medicina. Universidade de São Paulo. SP, Brasil

\section{Correspondence:}

Tais Renata Ribeira Parede

Departamento de Oftalmologia HCFMUSP

Av. Dr. Enéas de Carvalho Aguiar, 647

Cerqueira César

05403-000 São Paulo, SP, Brasil

E-mail: taisparede@hotmail.com

\section{Social costs of two cataract surgical techniques in Brazil}

\begin{abstract}
OBJECTIVE: To compare postoperative social costs of two cataract surgical techniques, phacoemulsification (PHACO) and extracapsular extraction (ECCE).

METHODS: Prospective randomized intervention study including 205 patients, of which 101 underwent PHACO and 104 ECCE in the public service, in the city of São Paulo, Southeastern Brazil, in 2002. The socioeconomic impact of these surgical procedures was assessed based on postoperative costs for patients, employers and social security. Comparisons between the two groups studied were performed using the chi-square test or Mann-Whitney test, when appropriate. A 5\% significance level was set.
\end{abstract}

RESULTS: Hospital and eyeglasses costs for PHACO were lower than for ECCE patients, with a mean difference of US\$ 16.74. Costs to employers related to medical leave for the first 15 days of absence and costs of caregivers in the form of absence from work to attend postoperative follow-up visits were on average US\$ 0.18 lower in PHACO compared to ECCE group. The estimated Social Security expenditure per patient undergoing surgery was US\$ 6.57 and US\$ 51.15 in PHACO and ECCE groups, respectively.

CONCLUSIONS: The average saving with PHACO compared to ECCE technique was US\$ 61.50 for employers, patients, caregivers and Social Security.

DESCRIPTORS: Cataract. Cataract Extraction. Ophthalmologic Surgical Procedures, rehabilitation. Health Expenditures. Employer Health Costs. Social Security. Costs and Cost Analysis.

\section{INTRODUCTION}

Cataract surgery with intraocular lens (IOL) implant is one of the ophthalmic surgical procedures most performed all over the world. ${ }^{1}$ Currently, the most widely used techniques for cataract surgery are manual extracapsular cataract extraction (ECCE) and phacoemulsification (PHACO). ${ }^{1}$ In most developed countries, PHACO is the most widely used technique due to its prompt visual recovery and low rate of intraoperative complications. ${ }^{9,11}$

It is estimated that for covering all emerging new cataract cases in Brazil it would be required to perform about 500,000 surgeries per year. ${ }^{a}$ According to the Brazilian Ministry of Health, ${ }^{\mathrm{b}}$ between 1996 and 1998, there were performed on average 132,000 cataract surgeries per year funded by the National Health

${ }^{a}$ Kara-Junior N. Cirurgia de catarata : aspectos sociais e eficiência de duas técnicas cirúrgicas (facoemulsificação e extração extracapsular) no sistema público de saúde brasileiro [associate professor thesis]. São Paulo: Faculdade de Medicina da USP; 2008.

b Ministério da Saúde. Frequência anual de cirurgias de catarata. Relatório técnico. Brasília; 2002. 
System (SUS). It is estimated that at that time around 171,000 cataract surgeries were performed in public and private care services. In 2002, approximately 300,000 cataract surgeries were performed at public services. There was then an increase in PHACO with foldable IOL implantation from 64,761 in 2006 to 130,498 in 2007. ' Cataract surgery by PHACO with foldable IOL implantation costs to SUS US\$ 294.95 and ECCE with rigid IOL costs US\$ $193.58 .{ }^{\mathrm{d}}$ Although SUS has covered PHACO cataract surgery since 2001 , ${ }^{\text {c }}$ its social advantages and disadvantages comparative to ECCE are not yet established given that the health budget is limited and its increased spending on a particular procedure entails reduced funding of others. Considering the scarcity of data in the literature, this study aimed to compare the socioeconomic impact of PHACO and ECCE cataract surgical procedures. ${ }^{\mathrm{a}}$

\section{METHODS}

A prospective randomized intervention study was conducted including 205 patients undergoing cataract surgery in a reference teaching hospital in the city of São Paulo, Southeastern Brazil, in 2002. We studied socioeconomic aspects associated with two surgical techniques for senile cataract extraction (ECCE and PHACO) and postoperative costs during the recovery period for patients, caregivers, employers and social security.

Patients with senile cataract with bilateral visual impairment (less than 20/40 on Snellen chart or 0.3 logMAR in the eye with better sight, with the best optical correction); living within an area of $100 \mathrm{~km}$ away from the hospital; baseline intraocular pressure (IOP) lower than $21 \mathrm{mmHg}$ (without treatment); and who were able to understand and answer the study questionnaire and signed an informed consent form were included in the study.

There were excluded patients with clinical or physical limitations causing impairment of daily life and professional activities; ocular abnormalities with reduction of visual acuity; amblyopia; previous eye surgeries; and who refused to participate in the study or sign the consent form.

The selected patients were randomly assigned to two groups: the PHACO group with 101 patients undergoing PHACO cataract surgery with foldable posterior chamber IOL implantation; and the ECCE group with 104 patients undergoing ECCE with rigid posterior chamber IOL implantation.

PHACO patients were followed up on Day 1, Day 7 and Day 21 (probable date of discharge) postoperatively. The final eyesight correction was prescribed at discharge as needed. They were asked to come in for an additional visit 30 days after discharge for study monitoring and clinical management.

ECCE patients were followed up on Day 1, Day 7, Day 28, Day 42 and Day 56 (probable date of discharge) postoperatively. Sutures were removed after Day 42 as needed with an additional follow-up visit scheduled for the next week. Eyesight correction was prescribed at discharge as needed.

For the financial social cost analysis of each procedure, individual costs with corrective eyeglasses, transportation and food in postoperative visits for both patients and caregivers were taken into account. Three and 5.70 follow-up visits were considered on average in the PHACO and ECCE group, respectively. Eyeglasses costs were estimated from the value of spherical and cylindrical components prescribed after surgery. The calculation was based on Optical Retail Industry prices for corrective monofocal lenses and basic frames without any additional treatment, ranging from US\$ 18.36 to US\$ 66.51. New corrective lenses were prescribed 180 days after surgery in case of change of one or more spherical/cylindrical diopters, or any change of 10 degrees or more in the axis of the astigmatism. In these cases, the frame cost was not added since the cost of a basic frame was included the first time, and the use of the original frame was considered in the purchase of new lenses after six months.

The cost to employers was calculated based on the average monthly wage of patients and workforce loss within 15 days after surgery due to medical leave. The estimated average loss per patient for employers was obtained by the percentage of employed patients in each group.

Cost to employers due to caregivers absence was estimated based on monthly wage of caregivers, percentage of employed caregivers, and number of follow-up visits required. It was assumed that caregivers were absent from work on visit days.

A social security benefit is paid to insurers when they are not able to work due to an illness or injury starting from the 15 th consecutive day of absence. For workers with a formal contract, in the first 15, days they are paid by the employer and from the 16th day of absence on, they are paid by Social Security. To assess social security costs, expenditures were estimated based on the average wage of employed patients. All patients were on leave of absence by the time of discharge.

Parametric values were analyzed by the chi-square test for independent samples and non-parametric values

\footnotetext{
c Ministério da Saúde. Sistema de Informações Ambulatoriais do SUS (SIA/SUS). [cited 2008 Jul 04]. Available from: http://tabnet.datasus.gov.br/ cgi/deftohtm.exe?sia/cnv/parf.def

d Secretaria da Saúde do Estado de São Paulo. Tabela do SUS para procedimentos ambulatoriais. São Paulo; 2002.
} 
using the Mann-Whitney test. The level of statistical significance was $5 \%(\mathrm{p}<0.05)$ in all tests.

Data analyses were performed in Access ${ }^{\circledR}$ (Office 1997). All statistical tests were performed with SPSS 10.0 .

The study was approved by the Research Ethics Committee of Hospital das Clínicas da Faculdade de Medicina da Universidade de São Paulo (Protocol $167 / 01$ on $04 / 26 / 2001$ ).

\section{RESULTS}

There were no differences in distribution of patients in both groups regarding age, gender and occupation. The mean age was 68.3 years $(\mathrm{SD}=9)$ and 69.1 years $(\mathrm{SD}=8.5)(\mathrm{p}=0.7)$ in the PHACO and ECCE group, respectively; $35.3 \%$ and $441 \%$ of patients were males, respectively $(\mathrm{p}=0.4)$.

Table 1 shows the occupational status of patients by surgical procedure. In the PHACO group, $16.8 \%$ of patients were employed and only 5\% were job seekers, despite their visual impairment. In the ECCE group, $13.5 \%$ were employed and only $3.8 \%$ were job seekers. Both groups primarily comprised economically inactive patients who were not motivated to look for a job.

Table 2 shows that no statistically significant difference was found between groups regarding average wage of employed patients $(p=0.13)$. PHACO and ECCE patients had an average wage of US\$195.42 (SD = 51.81) and US\$216.97, respectively.

Personal costs on transportation and food during follow-up visits after surgery were on average US\$ 11.00 and US\$ 18.92 in the PHACO and ECCE group, respectively.

The comparison of the estimated average cost for the purchase of eyeglasses shows that, although these costs

Table 1. Occupational status of patients by cataract surgical procedure. City of São Paulo, Southeastern Brazil, 2002. $(\mathrm{N}=205)$

\begin{tabular}{lcccccc}
\hline \multirow{2}{*}{$\begin{array}{l}\text { Occupational } \\
\text { status }\end{array}$} & \multicolumn{2}{c}{ PHACO } & \multicolumn{2}{c}{ ECCE } & \multicolumn{2}{c}{ Total } \\
& $\mathrm{n}$ & $\%$ & $\mathrm{n}$ & $\%$ & $\mathrm{n}$ & $\%$ \\
\hline Retired & 49 & 48.0 & 53 & 52.0 & 102 & 100.00 \\
Homemaker & 25 & 43.9 & 32 & 56.1 & 57 & 100.00 \\
Employed & 17 & 54.8 & 14 & 45.2 & 31 & 100.00 \\
JS & 5 & 55.6 & 4 & 44.4 & 9 & 100.00 \\
UEM/NJS & 5 & 83.3 & 1 & 16.7 & 6 & 100.00 \\
\hline p= 0.12 & \multicolumn{1}{l}{ PHACO: phacoemulsification; ECCE: extracapsular cataract } \\
extraction; \\
JS: job seekers; UEM/NJS: unemployed/non job seekers.
\end{tabular}

were higher in the ECCE than PHACO group (US\$ 136.00 vs. US\$ 129.20 , respectively), this difference was not statistically significant $(\mathrm{p}=0.3)$. Considering that $33.0 \%$ of PHACO and $37.6 \%$ of ECCE patients required new corrective lenses after 180 days of surgery, the average expenditure with a second pair of lenses was US\$ 14.80 and US\$ 17.95 in the PHACO and ECCE group, with a total average expenditure with eyeglasses in the first six months after surgery was US\$ 144.00 and US\$ 152.82, respectively.

Prescribed cylinder axis for corrective lenses ranged from one to two diopters in $33.7 \%$ and $46.2 \%$ in the PHACO and ECCE group, respectively. Cylindrical diopters greater than three degrees were prescribed in $6.0 \%$ of PHACO patients and $2.9 \%$ of ECCE patients.

The estimated average loss of employers within the first 15 days after surgery was US\$ 16.44 and US\$ 16.33 per patient in the PHACO and ECCE group, respectively. Based on the number of follow-up visits for each group and considering that caregivers lost a day of work for each postoperative visit, the average loss of employers due to caregiver absence at work was estimated at US\$ 9.11 and US\$ 9.40 per patient in the PHACO and ECCE group, respectively.

The average social security cost for each employed patient after 15 days of absence was estimated at US\$ 39.08 (six days) in the PHACO group and US\$ 380.07 in the ECCE group (47 days). Based on the percentage of employed patients in both groups (16.8\% in the PHACO and $13.5 \%$ in the ECCE group), the average expenditure of social security was estimated at US\$ 6.57 and US\$ 51.15 per patient in the PHACO and ECCE group.

Table 2 shows the comparison between groups of total average postoperative costs for patients, business (employers) and social security. No statistically significant difference was seen between groups ( $\mathrm{p}=$ 0.1 ), although total costs were higher in the ECCE than PHACO group (US\$ 248.62 vs. US\$ 187.12).

Table 2. Comparison of estimated total average cost including postoperative follow-up for employers, patients and social security. City of São Paulo, Southeastern Brazil, 2002.

\begin{tabular}{lcc}
\hline Subject & PHACO (US\$) & ECCE (US\$) \\
\hline Employers & 25,55 & 25,73 \\
Patients & 155,00 & 171,74 \\
Social Security & 6,57 & 51,15 \\
\hline Total & 187,12 & 248,62 \\
\hline
\end{tabular}

$p=0.10$

PHACO: phacoemulsification; ECCE: extracapsular cataract extraction 


\section{DISCUSSION}

Most developed countries have recently implemented PHACO surgical procedure to treat cataract. ${ }^{8}$ However, the economic viability of the implementation of this procedure in public health systems in developing countries has been questioned because of a potential increase in costs. In this context, more financial resource allocation for this procedure could entail fewer resources for other needs, reducing health system effectiveness. ${ }^{3,6,10}$

Public health expenditures range between US\$1,000 and US\$ 1,500 per person per year in developed countries like Japan, Canada and France while it is US\$ 80 per person per year in Brazil, which is below the amount required to provide adequate health care. It makes it even more imperative to minimize treatment costs without compromising quality of care. ${ }^{5}$

There are numerous barriers of access to cataract surgery in public services such as long waiting time for screening at the primary and secondary care levels, further delaying treatment. Community programs are crucial to minimize barriers of access to cataract surgery, so that patients can be diagnosed and surgery scheduled on the same day.

For those who were not employed before surgery, partly because of their visual impairment associated with cataract, there was an incentive to return to work after surgery, even though the patients analyzed were on average over 68 years of age. This is an important finding as it brings part of economically inactive population back into the labor market.

The total average savings of patients in the PHACO compared to the ECCE group was US\$ 16.74. Additional costs due to greater number of follow-up visits required in the ECCE group, as well as related to caregiver availability, may make it difficult adequate postoperative follow-up of patients in this group. Although the difference in the estimated average cost for patients in both groups was not statistically significant, the absolute cost (US\$ 16.74) is deemed high for a sample predominantly consisting of retired and economically inactive people. Thus there is an increased cost to social security when the ECCE procedure is used as reported by Kara-Júnior et al. ${ }^{7}$
For the business, the costs of both procedures are similar. The only advantage is that employees undergoing PHACO return to work earlier than those submitted to ECCE. Yet the estimated average cost for social security was much higher in ECCE patients. The substantial difference of US\$ 44.58 per patient should be computed on the sum of total public costs of ECCE surgery.

While PHACO cataract surgery with foldable IOL implantation is more costly than ECCE with rigid IOL, ${ }^{c}$ a cost difference of US\$ 101.37, reimbursement costs of both procedures should be compared against post-operative costs.

The present study estimated a total postoperative social cost of US\$ 187.12 for PHACO surgical procedure and US\$248.62 for ECCE. Taking into consideration SUS reimbursement costs for both procedures, the social cost of PHACO was US\$ 39.87 higher than that of ECCE, which is an acceptable amount due to its surgical advantages. ${ }^{9,11}$

Moreover, in both groups, most employed patients reported improved productivity after surgery. This fact alone may suggest the return on investment of the government with these surgical procedures and improved quality of life of patients as well.

One of the basic principles of public health economics is to implement streamlined actions that can provide cost savings without increasing health risks. Advances in treatment modalities in general require progressively more resources and, therefore, public health decisions should be justified based on the effectiveness of each procedure, which is critical for its implementation. The efficacy of a procedure is measured by improved quality of life of patients and the economic impact on the health system, as new costs entail reduced resources to other areas. ${ }^{2}$

Health cost savings are achieved through more reasonable spending that can produce higher social benefits at lower costs. ${ }^{3}$ Rather than posing new problems, the use of modern technology for cataract surgery in developing countries can help address them. ${ }^{4}$

In conclusion, the incentive and government investment in PHACO in the SUS is socially justified given its cost savings of 9.9\% (US\$16.92) for patients and business in the postoperative period, associated with social security savings of US\$ 44.58 and additional benefits for patients, caregivers and employers. 


\section{REFERENCES}

1. Albanis C, Dwyer MA, Ernest T. Outcomes of extracapsular cataract extraction and phacoemulsification performed in a University training program. Ophthalmic Surg Lasers. 1998;29(8):643-8.

2. Brown MM, Brown GC. How to interpret a healthcare economic analysis. Curr Opin Ophthalmol. 2005;16(3):191-4. DOI:10.1097/01. icu.0000164166.55550.68

3. Chang DF. Factoring cost, is phacoemulsification still the procedure of choice? Br / Ophthalmol. 2001:85(7):765-6. DOI:10.1136/bjo.85.7.765

4. Gillies M, Brian G, Nauze JL. Modern surgery for global cataract blindness: preliminary considerations. Arch Ophthalmol. 1998;116(1):90-2.

5. Kara-Junior N, Arieta CEL. Catarata senil. In: Kara-Jose N, Almeida GV, editores. Senilidade ocular. São Paulo: Roca; 2001. p.99-107.

6. Kara-Junior N, Avakian A, Lower LMT, Rocha AM, Cursino M, Alves MR. Facoemulsificação versus extração extracapsular manual do cristalino: análise de custos. Arq Bras Oftalmol. 2004;67(3):481. DOI:

\subsection{0/S0004-27492004000300021}

7. Kara-Junior N, Santhiago MR, Parede TRR, França RE, Sirtoli MGGM, Caravalho RS. Phacoemulsification versus extracapsular extraction: governamental costs. Clinics. 2010;65(4):357-61. DOI:10.1590/S180759322010000400002

8. Leaming DV. Practice styles and preferences of American Society of Cataract and Refractive Surgery (ASCRS) members-1998 Survey. J Cataract Refract Surg. 1999;25(6):851-9.

9. Lundstrom M, Stenevi U, Thorburn W. The Swedish National Cataract Register: a 9-year review. Acta Ophthalmol Scand. 2002;80(3):248-57. DOI:10.1034/ j.1600-0420.2002.800304.x

10. Minassian DC, Rosen P, Dart JKG. Extracapsular cataract extraction compared with small incision surgery by phacoemulsification: a randomised trial. Br J Ophthalmol. 2001;85(7):822-29. DOI:10.1136/ bjo.85.7.822

11. The Royal College of Ophthalmologists of London. Cataract surgery guidelines. Londres; 2001.

This article has received corrections asked by the editor on Jan/2011 in agreement with the ERRATUM published in Volume 45 Number 1.(http://www.scielosp.org/pdf/rsp/v45n1/corrigendum.pdf )

Article based on José Junior NK associate professor thesis presented at Universidade de São Paulo Faculdade de Medicina in 2008.

The authors declare that there are no conflicts of interest. 